\title{
Vibrio parahaemolyticus PRODUTORES DE UREASE ISOLADOS A PARTIR DE OSTRAS (Crassostrea rizophorae) COLETADAS IN NATURA EM RESTAURANTES E MEXILHÕES (Perna perna) DE BANCO NATURAL ${ }^{1}$
}

\author{
Chistiane Soares PEREIRA ${ }^{2, *}$, Célio Mauro VIANA ${ }^{3}$, Dália dos Prazeres RODRIGUES ${ }^{4}$
}

\begin{abstract}
RESUMO
A presença de Vibrio parahaemolyticus foi avaliada em 50 amostras de moluscos bivalves marinhos compostas por 40 amostras de ostras coletadas em 15 restaurantes do Rio de Janeiro e 10 amostras de mexilhões capturados de banco natural em Ponta de Itaipú - Niterói. Foram empregadas a técnica do Número Mais Provável (NMP) para a enumeração de V. parahaemolyticus utilizando Caldo Glicosado Salgado com Teepol (GSTB) e Água Peptonada Alcalina (APA) com 3\% de cloreto de sódio (NaCl). Paralelamente foi realizada técnica de enriquecimento em APA com 1 e 3\% de $\mathrm{NaCl}$. Decorrido o período de incubação de ambas as técnicas, foi realizado plaqueamento em ágar TCBS (Tiossulfato Citrato Bile Sacarose). Todas as cepas de $V$. parahaemolyticus isoladas através das duas técnicas foram testadas para o fenômeno de Kanagawa e, quanto à produção de urease. Do total de 141 cepas de V. parahaemolyticus isoladas, $62 \%$ revelaram-se urease positivas e, dentre estas, os sorotipos predominantes foram O10:K?, O11:K? e O3:K57 dentre o total de 24 sorotipos urease positivos identificados. Embora todas as cepas de V. parahaemolyticus tenham sido Kanagawa negativas, os resultados apontam elevada incidência desta espécie em ostras comercializadas em restaurantes.
\end{abstract}

Palavras-chave: Vibrio parahaemolyticus; ostras; urease; gastrenterite.

\section{SUMMARY}

Vibrio parahaemolyticus UREASE POSITIVE ISOLATED FROM IN NATURA OYSTERS (Crassostrea rizophorae) COLLECTED AT RESTAURANTS AND MUSSELS (Perna perna) HARVESTED FROM NATURAL HABITAT. The presence of Vibrio parahaemolyticus were detected in 50 marine bivalve mollusks composed by 40 oysters samples collected at 15 restaurants in Rio de Janeiro City and 10 wild mussels' samples harvested in Ponta de Itaipu-Niterói. The Most Probable Number (MPN) technique was employed for the enumeration of V. parahaemolyticus, using Glucose Salt Teepol Broth (GSTB) and Alcaline Peptone Water (APW) with 3\% NaCl. At the same time, the samples were submitted on direct plating with APW added 1 and $3 \% \mathrm{NaCl}$. Both techniques were followed by plating onto TCBS agar. All the $V$. parahaemolyticus strains isolated were tested for Kanagawa phenomenon and they were also tested for the presence of urease. A total of $141 \mathrm{~V}$. parahaemolyticus strains were detected, $62 \%$ revealed urease positive and these strains were serological characterized showing the predominance of serotypes: 010:K?, 011:K? and O3:K57 among 24 serotypes urease positive. Although, all strains of $V$. parahaemolyticus were Kanagawa negative the results suggest a high incidence of these microorganism in oysters consumed.

Keywords: Vibrio parahaemolyticus; oysters; urease; foodborne disease.

\section{1 - INTRODUÇÃO}

Vibrio parahaemolyticus, importante espécie do gênero Vibrio, foi isolado pela primeira vez em 1951 no Japão, a partir de um surto de gastrenterite ocasionado pela ingestão de shirasu (sardinhas novas, semidessecadas) não submetidas à cocção. Atualmente, este microrganismo tem sido reconhecido, como um importante patógeno, capaz de determinar manifestações gastrentéricas após o consumo de pescado e moluscos bivalves sem cocção ou insuficientemente cozidos [3, $4,7,24,28]$.

Essa espécie encontra-se amplamente distribuída no ambiente aquático, particularmente salino. As cepas isoladas a partir de ambiente marinho, em sua maioria, não são patogênicas enquanto, aquelas pro-

\footnotetext{
Recebido para publicação em 21/01/2003. Aceito para publicação em 20/08/2004 (001059).

2. Avenida Nossa Senhora de Fátima, 74 - apto 101 - Centro - Bairro de Fátima, Rio de Janeiro-RJ. CEP: 20240-051. E-mail: csoarespereira@ hotmail.com

3. Departamento de Microbiologia de Alimentos - Faculdade de Veterinária-Universidade Federal Fluminense. Rua Vital Brasil Filho, s/n, Santa Rosa, Rio de Janeiro-RJ. CEP: 20240-091

4. Departamento de Bacterioilogia - $3^{\circ}$ andar - Instituto Oswaldo Cruz, Fiocruz. CEP: 21045-900

* A quem a correspondência deve ser enviada.
}

venientes de isolados clínicos são Kanagawa positivas, ou seja, induzem a reação de beta hemólise nos eritrócitos humanos. A proporção de cepas produtoras de gastrenterite varia de acordo com as condições geográficas e sazonais, portanto a freqüência de isolamento é maior, nos meses de verão, quando podem ocorrer surtos ou casos esporádicos de gastrenterite, após consumo de água ou alimentos marinhos contaminados [8, $9,12,15,23,30]$.

É interessante ressaltar que algumas evidências apontam que eventuais cepas de Vibrio parahaemolyticus Kanagawa positivas isoladas de ambiente aquático podem ter como reservatório os sedimentos aquáticos e a carapaça quitinosa de moluscos e copépodes. Essa característica contribuiria para a distribuição e ciclo anuais da bactéria no sistema estuarino [15, 16, 31].

Os principais fatores, incriminados como promotores da hemólise do fenômeno de Kanagawa são as hemolisinas TDH (Thermoestable Direct Hemolysin) e TRH (Thermoestable Related Hemolysin) consideradas importantes fatores de virulência [23, 26]. Estudos recentes indicaram que cepas Kanagawa negativas podem ser capazes de provocar infecção gastrentérica em humanos indicando a possibilidade de existência de mais de um fator de virulência no desencadeamento das infecções [13]. Foi observado que algumas cepas possuem a capacidade de hidrolisar uréia e freqüente- 
mente são isoladas a partir de casos clínicos sugerindo uma forte associação entre positividade ao fenômeno de Kanagawa, hidrólise de uréia e presença de TDH ou TRH [4, 6, 14, 20, 22].

Tendo em vista, a importância desse patógeno e sua veiculação através do consumo de alimentos oriundos do ambiente marinho, objetivou-se na presente investigação, identificar a presença de Vibrio parahaemolyticus em amostras de moluscos bivalves coletados em restaurantes do Rio de Janeiro e, verificar o potencial patogênico da bactéria através do teste de Kanagawa, caracterização antigênica e avaliação da produção de urease.

\section{2 - MATERIAL E MÉTODOS}

Foram analisadas 50 amostras de moluscos bivalves marinhos ("pool" de doze unidades amostrais), no período de julho de 1997 a fevereiro de 1998, compostas por 40 amostras de ostras (Crassostrea rhizophorae), adquiridas de 15 restaurantes no Rio de Janeiro e 10 amostras de mexilhões (Perna perna) coletadas diretamente de seu habitat em Ponta de Itaipú - Niterói.

As ostras e mexilhões coletados foram acondicionados em sacos de polietileno devidamente identificados com etiqueta auto-adesiva. O transporte foi efetuado em caixas de isopor contendo gelo reciclável, evitando-se submeter as amostras a temperaturas superiores a $10^{\circ} \mathrm{C}$ e inferiores a $2^{\circ} \mathrm{C}$, assim como, contato direto com gelo ou outras superfícies frias. As amostras foram transportadas num prazo não excedente à duas horas ao Laboratório de Enterobactérias, Departamento de Bacteriologia do Instituto Oswaldo Cruz FIOCRUZ.

Para retirada do conteúdo corpóreo as valvas foram lavadas em água corrente, escovadas vigorosamente para a retirada das sujidades e secas com papel toalha. Em seqüência, os moluscos foram abertos assepticamente com auxílio de faca e bisturi de lâmina fixa, ambos esterilizados, sendo a parte corpórea e o líquido intervalvar recolhidos em placa de Petri esterilizada e pesadas 25 gramas da amostra a qual adicionou-se $225 \mathrm{~mL}$ de solução salina tamponada $(\mathrm{pH} 7,2)[11,29]$.

A partir da diluição $10^{-1}$, foi realizada a enumeração do Vibrio parahaemolyticus seguindo-se a técnica de Número Mais Provável (NMP) utilizando-se como meios de cultura o caldo GSTB (Glicose Sal Teepol) e caldo APA (Água Peptonada Alcalina) com 3\% de $\mathrm{NaCl}$, em três séries de três tubos em diluições decimais e consecutivas $\left(10^{-2}, 10^{-3}\right.$ e $\left.10^{-4}\right)$, as quais permaneceram por 24 horas em estufa a $37^{\circ} \mathrm{C}$ [11].

De cada série de tubos contendo GSTB e APA com $3 \%$ de $\mathrm{NaCl}$ com crescimento, procedeu-se o plaqueamento através da semeadura em ágar TCBS (Tiossulfato Citrato Bile Sacarose) incubado em estufa bacteriológica a $37^{\circ} \mathrm{C}$ por 24 horas.

Paralelamente, foi realizada a técnica de enriquecimento direto em APA com 1\% e 3\% de cloreto de sódio
(NaCl). Após 24 horas de incubação a $37^{\circ} \mathrm{C}$, procedeu-se à semeadura em ágar TCBS.

Decorrido o período de incubação (overnight) das placas de TCBS, todas as cepas suspeitas de Vibrio parahaemolyticus oriundas das técnicas de enumeração e enriquecimento direto foram submetidas a uma confirmação preliminar utilizando-se os seguintes testes: crescimento em Agar Kligler-Ferro (KIA-Oxoid), Agar Lisina-Ferro (LIA-Oxoid) e produção da enzima citocromooxidase, a partir de Agar nutriente com 1\% de $\mathrm{NaCl}$.

Para identificação conclusiva das amostras, foram avaliadas as seguintes características metabólicas: oxidação/fermentação da glicose, fermentação de sacarose, arabinose e manose, capacidade de crescimento em diferentes concentrações salinas $(0,3,6,8$ e 10\%), utilização de aminoácidos (lisina-ornitina descarboxilase e arginina dehidrolase), produção de acetona no meio Voges Proskauer, produção de $\mathrm{H}_{2} \mathrm{~S}$ e mobilidade em meio SIM, produção de ONPG ( $\alpha$ nitrofenil- $\beta$-D galactosidase) e resistência ao agente vibriostático O/129 (fosfato de 2,4 diamino-6, diisopropil-pteridina) [29].

Todas as cepas identificadas bioquimicamente como Vibrio parahaemolyticus foram submetidas ao teste de Kanagawa em Agar Wagatsuma a fim de verificar sua patogenicidade através da hemólise total dos eritrócitos humanos. Foram ainda submetidas à caracterização antigênica para identificação do sorotipo. Essa prova foi realizada em placa de vidro para observação da aglutinação das cepas frente aos soros mono e polivalentes produzidos por Denka Seiken Co. Ltda, Tókio, Japão. Em seqüência, foi avaliada a produção de urease em meio Agar Uréia de Christensen empregando-se diferentes concentrações de $\mathrm{NaCl}(0,5 \%, 1 \%$ e 3\%) [11].

\section{3 - RESULTADOS E DISCUSSÕES}

Na presente investigação, a análise das 50 amostras de moluscos bivalves marinhos (ostras e mexilhões) permitiu o isolamento de 141 cepas de Vibrio parahaemolyticus. Utilizando a técnica do Número Mais Provável (NMP), foram isoladas 60 cepas do patógeno assim distribuídas: 23 cepas $(38,3 \%)$ a partir do GSTB e 37 cepas $(61,6 \%)$ a partir do APA com $3 \%$ de NaCl. Ressalta-se que essas cepas isoladas foram detectadas em sua maioria a partir das amostras de ostras $(86,4 \%)$ e em menor proporção $(13,5 \%)$ a partir dos mexilhões.

A técnica de enriquecimento direto utilizando APA com 1 e 3\% de $\mathrm{NaCl}$ permitiu isolar 81 cepas de Vibrio parahaemolyticus. Das amostras de ostras foram isoladas 80 cepas da bactéria sendo que $45(55,5 \%)$ a partir do APA com 1\% de cloreto de sódio e 35 (44,4\%) oriundas do APA com 3\% de $\mathrm{NaCl}$. Por outro lado, apenas uma cepa desse patógeno foi isolada a partir do APA com 3\% de $\mathrm{NaCl}$ originária das amostras de mexilhões.

A técnica de enumeração de Vibrio parahaemolyticus (Número Mais Provável - NMP), demonstrou resultados mais significativos quando utilizado o meio APA adicionado de $3 \%$ de cloreto de sódio quando comparado com os resultados do meio GSTB. Por outro lado, a 
técnica de enriquecimento direto, o APA com $1 \%$ de $\mathrm{NaCl}$ apresentou melhores índices de isolamento em relação ao APA com 3\% de $\mathrm{NaCl}$ no que se refere as amostras de ostras. Porém, ressalta-se que a única cepa da bactéria isolada a partir de mexilhões originou-se do APA com 3\% de NaCl. Na época do estudo, os resultados da técnica de Número mais Provável (NMP) utilizando GSTB e APA adicionado de 3\% de cloreto de sódio, apresentaram-se em valores abaixo do número máximo permitido pela legislação nacional vigente [2]. Os baixos índices observados com relação à técnica de NMP podem ser resultantes da baixa concentração salina do meio ambiente, em especial daquelas amostras provenientes de mangue ou ainda de águas estuarinas [27].

Embora, as amostras de moluscos estivessem dentro dos parâmetros vigentes, é necessário que algumas informações sejam difundidas como a importância do uso de processos de depuração, corretas condições de estocagem sob refrigeração $\left(4-8^{\circ} \mathrm{C}\right)$ e manipulação em condições adequadas de higiene. Este conjunto de ações reduz a multiplicação de patógenos, prevenindo a ocorrência de enfermidades de transmissão alimentar, bem como, a contaminação cruzada e a recontaminação dos alimentos preparados. É importante salientar que a cocção representa o método mais eficaz para que o alimento seja considerado seguro para o consumo humano, do ponto de vista microbiológico [2, 21].

Devido a sua relevância epidemiológica, todas as cepas de $V$. parahaemolyticus isoladas foram analisadas quanto ao potencial patogênico através do fenômeno de Kanagawa, caracterizado por uma zona de beta hemólise ao redor do crescimento em meio ágar Wagatsuma, induzido pela hemolisina TDH. No entanto, nenhuma das cepas avaliadas apresentou positividade frente a esse teste, sendo consideradas não-patogênicas. Esse resultado está de acordo com dados de LEITÃO \& ARIMA [17] e RODRIGUES \& HOFER [25], quando afirmaram que cepas deste patógeno isoladas a partir de ambiente marinho apresentam pouca ou nenhuma atividade hemolítica. Entretanto, estudos demonstraram que amostras Kanagawa negativas podem não estar completamente isentas de patogenicidade [13].

As controvérsias a respeito do teste de Kanagawa fundamentam-se, também, no fato de que algumas espécies de Vibrio podem induzir hemólise no ágar Wagatsuma como é o caso do $V$. vulnificus, $V$. cholerae não- $\mathrm{O}_{1}, V$. mimicus e $V$. hollisae. Essas espécies são portadoras de uma hemolisina semelhante a TDH e, com base nestas observações o teste de Kanagawa deve ser considerado somente como um indicador de patogenicidade, não sendo utilizado como critério fundamental de diferenciação entre espécies [5].

A habilidade de hidrolisar uréia é mencionada por alguns autores como indicador da presença de TDH e TRH [6, 22]. OSAWA et al. [20], encontraram amostras urease positivas das quais menos de $6 \%$ eram carreadoras de TDH, sendo a grande maioria carreadora de TRH. Essa evidência sugere que a hidrólise da uréia não é um marcador seguro para identificar a TDH em $V$. parahaemolyticus, porém pode ser utilizada como marcador de TRH. Como todas as cepas analisadas nessa investigação foram Kanagawa negativas esse dado sugere não estar presente a TDH. Estudos complementares devem ser realizados para verificar a possivel presença de TRH como especulado por HONDA et. al., [14] que isolaram cepas Kanagawa negativas produtoras de uma hemolisina diferente da TDH e TRH, mas semelhante a ambas denominada TDH/I.

O teste de utilização da hidrólise de uréia como indicador de patogenicidade foi realizado através do crescimento das cepas isoladas em meio agar uréia de Christensen utilizando 3 diferentes concentrações salinas $(0,5 \%, 1 \%$ e $3 \%)$. Das 141 cepas avaliadas, 51 (36\%) apresentaram-se produtoras de urease. Um total de 40 cepas $(78,4 \%)$ foram capazes de desenvolver-se no meio agar uréia de Christensen adicionado de $1 \%$ de $\mathrm{NaCl}$. Por outro lado, 9 cepas $(17,6 \%)$ foram capazes de crescer no mesmo meio adicionado de $0,5 \%$ de $\mathrm{NaCl}$ enquanto que apenas duas cepas (4\%) foram capazes de crescimento no meio adicionado de $1 \%$ de $\mathrm{NaCl}$. O tratamento estatístico (Teste t), para esse parâmetro apresentou diferença significativa entre as concentrações salinas empregadas, assim sendo a adição de $1 \%$ de $\mathrm{NaCl}$ foi recomendada devido aos baixos níveis de isolamento em concentrações inferiores $(0,5 \%)$ ou superiores $(3 \%)$.

Das 141 cepas de V. parahaemolyticus isoladas, 5 cepas apresentaram-se rugosas impossibilitando sua caracterização antigênica, sendo que 4 destas eram provenientes de amostras de ostras e 1 cepa oriunda de mexilhões. Portanto, foram analisadas 136 cepas oriundas das amostras de ostras as quais apresentaram 45 sorotipos diferentes assim distribuídos: O10:K? (22) O1:K? (9), O5:K17 (8), O8:K? (8), O2:K28 (7), O10:K69 (6), O2:K3 (5), O3:K57 (5), O3:K72 (5), O $11: K ?(5), \mathrm{O} 2: \mathrm{K}$ ? (4), O4:K? (4), O4:K42 (3), O10:K52 (3), O11:K19 (3), O1:K32 (2), O3:K33 (2), O4:K34 (2), O5:K47 (2), O1 1:K34 (2), O1:K12 (1), O1:K33 (1), O2:K25 (1), O2:K30 (1), O3:K? (1), O3:K5 (1), O3:K6 (1), O3:K30 (1), O3:K31 (1), O3:K36 (1), O4:K12 (1), O5:K25 (1), O6:K? (1), O8:K11 (1), O8:K39 (1), O8:K41 (1), O9:K? (1), O10:K7 (1), O10:K25 (1), O10:K31 (1), O10:K60 (1), O11:K22 (1), O11:K36 (1) e O11:K40 (1). Desses 45 sorotipos identificados, 40\% eram conhecidos, $38 \%$ novos e $22 \%$ não foi possível identificar o antígeno $\mathrm{K}(?)$.

Dentre as 141 cepas totais de $V$. parahaemolyticus, 51 foram urease positivas e dentro dos resultados de caracterização antigênica citado anteriormente, os 24 sorotipos urease positivos foram: O10K? (9), O3:K57 (4), O5:K17 (4), O1:K? (3), O2:K3 (2), O4:K42 (3), O8:K? (3), O11:K? (2), O11:K19 (2), O1:K32 (1), O2:K? (1), O3:K5 (1), O3:K6 (1), O3:K30 (1), O3:K33 (1), O3:K72 (1), O3:K? (1), O4:K? (1), O5:K? (1), O5:K25 (1), O10:K52 (1), O10:K60 (1) O11:K36 (1)e O11:K40 (1). Cabe ressaltar que 4 cepas urease positivas apresentaram-se rugosas impossibilitando sua caracterização antigênica.

De acordo com FISHBEIN \& WENTZ [10], os sorotipos isolados a partir de amostras clínicas freqüente- 
mente não correspondem àqueles encontrados no ambiente. BINTA \& NYAGA [1], sorotiparam 74 cepas de $V$. parahaemolyticus, dentre as quais, destacaram-se os sorotipos O10:K52 e O11:K40 identificados, também, no presente estudo. Os referidos autores citaram que Barrow (1974) considerou o sorotipo O11:K40 no grupo daqueles envolvidos em infecção alimentar. Pelo que se pode observar, o sorotipo O11:K40 foi isolado nesta pesquisa a partir de moluscos bivalves marinhos.

RODRIGUES \& HOFER [25], por sua vez, identificaram a partir de ostras, alguns dos sorotipos detectados na presente investigação (O2:K28 e O3:K?) do mesmo modo que MAGALHÃES et. al. [18], O3:K5 e O10:K? e MONTAGUE, LeCLAIR \& YOJI [19], O2:K28, O5:K17 e O4:K12. Ressalta-se que o sorotipo O3:K6 considerado novo ou emergente em algumas regiões dos Estados Unidos foi identificado nesse estudo a partir de uma cepa de $V$. parahaemolyticus [7].

Durante as colheitas, observou-se que o hábito de consumo de ostras, nos restaurantes avaliados, ocorre in natura com algumas gotas de limão e os mexilhões apenas levemente aquecidos para abertura das valvas e retirada da parte corpórea do molusco, a qual é consumida depois de temperada, sem cozimento. Pesquisa realizada por VITELA \& ESCARTIN [30], em pescado fresco e "ceviche" adicionados de limão, permitiu concluir que a acidificação do alimento não exerce poder bactericida sobre o Vibrio cholerae, de forma que, o alimento não foi considerado seguro para consumo sem cocção. Isto reforça a assertiva sobre o risco do consumo de moluscos bivalves sem prévio cozimento podendo resultar em infecções provocadas por diferentes microrganismos, particularmente aqueles pertencentes ao gênero Vibrio.

A desinformação a respeito dos riscos, especialmente para indivíduos portadores de infecções crônicas ou degenerativas, de consumir moluscos bivalves marinhos sem cocção, representa um fator adicional à probabilidade de ocorrência de casos isolados, surtos gastrentéricos ou outras patologias envolvendo o consumo desse alimento contaminado com espécies do gênero Vibrio [21]. A patogenicidade dessas espécies, em especial do $V$. parahaemolyticus merece estudos adicionais para que os esclarecimentos com relação a esse dado possam ofertar subsídios, para prevenir as conseqüências, resultantes do consumo de moluscos bivalves sem cocção, insuficientemente cozidos ou sob sua forma in natura.

Outro aspecto altamente relevante refere-se à manutenção de ostras e mexilhões por longos períodos sem refrigeração. A temperatura ambiente favorece a multiplicação em grande número de microrganismos, particularmente $V$. parahaemolyticus, que possui um tempo de geração curto, cerca de 10 minutos [32]. O ideal é que os moluscos bivalves marinhos sejam conservados sob refrigeração $\left(4^{\circ} \mathrm{C}\right)$ em ambiente limpo, sanitizado e cozidos a temperatura de $100^{\circ} \mathrm{C}$ por aproximadamente 30 minutos a fim de inativar possiveis patógenos bacterianos presentes. Ressalta-se a importância do cumprimento das regras básicas de higiene que auxiliam no combate a contaminação cruzada ou recontaminação do alimento pronto para consumo. Essas práticas adotadas em conjunto auxiliam na transformação do consumo de moluscos bivalves marinhos em um hábito alimentar seguro do ponto de vista microbiológico e da saúde pública.

\section{4 - CONCLUSÕES}

Os moluscos bivalves marinhos analisados na presente investigação, embora aptos para o consumo humano segundo a legislação brasileira vigente na época do estudo [2], apresentaram índices relevantes de isolamento de Vibrio parahaemolyticus, cujos testes de patogenicidade apresentaram cepas produtoras de urease e sorotipos reconhecidos como patogênicos em casos de surtos de gastrenterite. Esses dados reforçam a importância de pesquisas microbiológicas aprofundadas sobre o patógeno e seus reais riscos para a saúde do consumidor quando presentes em alimentos de origem marinha.

\section{5 - REFERÊNCIAS BIBLIOGRÁFICAS}

[1] BINTA, M.G.; NYAGA, P.N. The distribution of Vibrio parahaemolyticus serotypes in Kenyan seafish, shellfish, marine water and sediments. Trans. Roy. Soc. Trop. Med. Hyg., v. 76, n. 4, p. 497-9, 1982.

[2] BRASIL, Ministério da Agricultura, Secretaria Nacional de Vigilância Sanitária; Divisão Nacional de Vigilância Sanitária. Portaria 451 de 19 de setembro de 1997. Diário Oficial da República Federativa do Brasil, Brasília, 22 de setembro de 1997.

[3] CENTERS FOR DISEASE CONTROL AND PREVENTION. Outbreak of Vibrio parahaemolyticus infections associated with eating raw oysters - Pacific Northwest, 1997. Morb. Mortal. Wkly. Rep., v. 47, n. 22, p. 457-62, 1998.

[4] CENTERS FOR DISEASE CONTROL AND PREVENTION. Outbreak of Vibrio parahaemolyticus infections associated with eating raw oysters and clams harvested from Long Island Sound - Connecticut, New Jersey, and New York, 1998. Morb. Mortal. Wkly. Rep., v. 48, n. 3, p. 48-5, 1999.

[5] CHATTERJEE, B.D., GORBACH, S.L., NEOGY, K.N. Vibrio parahaemolyticus and diarrhoea associated with noncholerae Vibrio. Bull.Wor. Hea. Org., v. 42, n. 3, p. 460-3, 1970.

[6] COOK, D.W.; BOWERS, J.C.; DePAOLA, A. Density of total and pathogenic (tdh+) Vibrio parahaemolyticus in Atlantic and Gulf Coast molluscan shellfish at harvest. J. Food Prot., v. 65, n. 12, p. 1873-80, 2002.

[7] DANIELS, N.A.; RAY, B.; EASTON, A.; MARANO, N.; KAHN, E.; MCSHAN, A.L.; DEL ROSARIO, L.; BALDWIN, T.; KINGSLEY, M.A.; PUHR, N.D.; WELLS, J.G.; ANGULO, F.J. Vibrio vulnificus and a new Vibrio parahaemolyticus serotype in raw oysters. JAMA, v. 284, n. 12 , p. 1541-45, 2000 .

[8] DePAOLA, A.; NORDSTROM, J.L.; BOWERS, J.C.; WELLS, J.C.; COOK, D.W. Seasonal abundance of total and pathogenic Vibrio parahaemolyticus in Alabama oysters. Appl. Envir. Mircrob., v. 69, n. 3, p. 1521 26, 2003. 
[9] ELliSON, R.K.; MALNATI, E.; DePAOLA, A.; BOWERS, J.C.; RODRICK, G.E. Populations of Vibrio parahaemolyticus in retail oysters from Florida using two methods. J. Food. Prot., v. 64, n. 5, p. 682-86, 2001.

[10] FISHBEIN, M.; WENTZ, B. Vibrio parahaemolyticus methodology for isolation from seafoods and epidemic specimens. J. Milk Food. Tech., v. 36, n. 2, p. 118$23,1973$.

[11] FOOD AND DRUG ADMINISTRATION (FDA)Bacteriological Analytical Manual $8^{\mathrm{a}}$ ed., Vibrio cholerae, Vibrio parahaemolyticus and other Vibrio spp. http:// vm.cfsan.fda.gov/ ebam/bam-9.html acesso em 03/09/ 1997.

[12] HAGEN, C.J.; SLOAN, E.M.; LANCETTE, G.A.; PEELER, J.T.; SOFOS, J.N. Enumeration of Vibrio parahaemolyticus in various seafoods with two enrichment broths. J. Food. Prot. v. 57, n. 5, p. 40309, 1994.

[13] HONDA, T.; LAPUEBLA, M.A.A.; NI, Y.; YAMAMOTO, K. Characterization of a new thermostable direct haemolysin produced by Kanagawa-phenomenon negative clinical isolate of Vibrio parahaemolyticus. J. Gen. Microb., v. 137, n. 2, p. 253-9, 1991.

[14] HONDA, S.; MATSUMOTO, S.; MIWATANI, T.; HONDA, T. A survey of urease positive Vibrio parahaemolyticus strains isolated from traveler's diarrhea, seawater and imported frozen. Eur. J. Epidem., v. 8, n. 6, p. 861-4, 1992.

[15] KANEKO, T.; COLWELL, R.R. Adsorption of Vibrio parahaemolyticus onto chitin and copepods. App1. Microb., v. 29, n. 2, p. 269-74, 1975.

[16] KARUNASAGAR, I.; VENUGOPAL, M.N.; KARUNASAGAR, I.; SEGAR, K. Role of chitin in the survival of Vibrio parahaemolyticus at different temperatures. Can. J. Microb., v. 32, n. 3, p. 889-90, 1986.

[17] LEITÃO, M.F de F.; ARIMA, H.K. Vibrio parahaemolyticus no ambiente marinho do Estado de São Paulo. Ocorrência na água e avaliação da metodologia para isolamento. Col. Inst. Tec. Ali., v. 6, n. 2, p. 149-66, 1975.

[18] MAGALHāES, V.; LIMA, R.A.; TATENO, S.; MAGALHÃES, M. Gastroenterites humanas associadas a Vibrio parahaemolyticus no Recife, Brasil. Rev. Ins. Med. Trop. S. Paulo, v. 1, n. 33, p. 64-8, 1991.

[19] MONTAGUE, T.S.; LeClAIR, R.A.; YOJI, H.Z. Typing of $\mathrm{O}$ antigens of Vibrio parahaemolyticus by a slide agglutination test. Appl. Microb., v. 21, n. 5, p. 94959, 1971.

[20] OSAWA, R.; OKITSU, T.; MOROZUMI, H.; YAMAI, S. Occurrence of urease-positive Vibrio parahaemolyticus in Kanagawa, Japan, with specific reference to presence of Thermoestable Direct Hemolysin Genes. Appl. Env. Microb., v. 62, n. 2, p. 725-7, 1996.
[21] OTWELL, W.S. Ready to eat Seafoods. Important Food Safety Considerations. http://vm.cfsan.fda.gov/ ear/ FLRTESEA.html, acesso em 03/09/97.

[22] PARK, K.S.; LIDA, T.; YAMAICHI, Y.; OYAGI, T.; YAMAMOTO, K.; HONDA T. Genetic characterization of DNA region containing the trh and ure genes of Vibrio parahaemolyticus. Infect. Immun., v. 68 , n. 10, p. 5742$48,2000$.

[23] REALI, D.; CAROLI, G.; FILIPPI, S.; SIMONETTI, S. Sulla presenza e dignificato etio-epidemiologico di vibrioni alofili in materiali vari. Boll. Ist. Sier. Mil., v. 56, n. 3, p. 206-11, 1977.

[24] RIPPEY, S.R. Infectious diseases associated with molluscan shellfish consumption. Clin. Microb. Rev., v. 7 , n. 4, p. 419-25, 1994.

[25] RODRIGUES, D.P.; HOFER, E. Vibrio species from the water-oyster ecosystem of Sepetiba Bay in Rio de Janeiro State Brazil. Rev. Microb., v. 4, n. 17, p. 332-8, 1986.

[26] SARKAR, B.L.; KUMAR, R.; DE, S.P.; PAL, S.C. Hemolytic activity of and lethal toxin production by environmental strains of Vibrio parahaemolyticus. Appl. Env. Microb., v. 53, n. 11, p. 2696-8, 1987.

[27] SAYLER, G.S.; NELSON JR, J.D.; JUSTICE, S.; COLWELL, R.R. Incidence of Salmonella spp., Clostridium botulinum and Vibrio parahaemolyticus in an estuary. Appl. Env. Microb., v. 31, n. 5, p. 723-30, 1976

[28] SOUSA, O.V. de; VIEIRA, R.H. dos F.; MENEZES, F.G.R. de; REIS, C.M.F. dos; HOFER, E. Detection of Vibrio parahaemolyticus and Vibrio cholerae in oyster, Crassostrea rizophorae, collected from a natural nursery in the Cocó River Estuary, Fortaleza, Ceará, Brazil. Rev. Inst. Med. Trop. S. Paulo, v. 46, n. 2, p. 59-62, 2004.

[29] VANDERZANT, C.; SPLITTSTOESSER, D.F. Compendium of methods for the microbiological examination of foods. $3^{\text {a }}$ ed. Washington: American Public Health Association (APHA), 919p, 1992.

[30]VITELA, M.R.T.; ESCARTIN, E.F. Incidence of Vibrio parahaemolyticus in raw fish, oysters and shrimps. Rev. Lat. Microb., v. 35, n. 3, p. 267-72, 1993.

[31] WEST, P.A. The human pathogenic vibrios- A public health update with environmental perspectives. Epidem. Infec., v. 103, n. 1, p. 1-34, 1989.

[32] YOJI, H.Z.; SAKAI,S.; TERAYAMA, T.; KUDO, Y.; ITO, T.; BENOKI, M.; NAGASAKI, M. Epidemiology, enteropathogenicity and classification of Vibrio parahaemolyticus. J. Infec. Dis., v. 115, n. 5. p. 43644, 1965.

\section{6 - AGRADECIMENTOS}

Ao CNPq (Conselho Nacional de Desenvolvimento Científico e Tecnológico) pelo apoio financeiro que possibilitou o desenvolvimento deste trabalho. 